\title{
Prediksi Kekuatan Gempa Bumi Indonesia Berdasarkan Nilai Magnitudo Menggunakan Neural Network
}

\author{
Oman Somantri ${ }^{1 *}$ \\ 1,2,3 Jurusan Teknik Informatika, Politeknik Negeri Cilacap, Indonesia \\ -oman_mantrieyahoo.com \\ *Correspondingauthor email:oman_mantri@yahoo.com
}

\begin{abstract}
Abstrak - Pada artikel ini diusulkan sebuah model untuk memprediksi kekuatan nilai magnitude gema bumi di Indonesia. Model yang dusulkan adalah metode neural network yang sebelumnya telah dioptimasi nilai parameter yang digunakannya dengan mengggunakan algoritma genetika sehingga tingkat error yang dihasilkan lebih kecil dan lebih baik. Berdasarkan hasil ekperimen didapatkan nilai root mean square error (RMSE) dari model neural network yang diusulkan adalah sebesar 0,718. Upaya peningkatan akurasi setelah dioptimasi dengan menggunakan algoritma genetika (GA) didapatkan hasil nilai RMSE sebesar 0,708. Berdasarkan hasil yang telah didapatkan maka terjadi peningkatan akurasi dengan dibuktikan adanya penurusan nilai RMSE yang teah didapatkan. Model yang diusulkan merupakan model terbaik yang dapat digunakan untuk memprediksi kekuatan nilai magnitudo gempa bumi denagn tingkat akurasi yang lebih baik dan nilai error yang lebih kecil.
\end{abstract}

Kata Kunci-gempa bumi, magnitude, neural network

\section{Pendahuluan}

Salah satu bencana alam yang tidak bisa terhindarkan oleh setiap bangsa saat ini adalah gempa bumi. Gempa bumi merupakan bencana yang tidak bisa diprediksikan kapan dan dimana terjadi bencana tersebut [1]. Saat ini banyak sekali para peneliti yang berusaha untuk memprediksikan kapan dan dimana terjadinya gempa tersebut sebelum terjadinya kejadian, akan tetapi sampai saat ini yang bisa dilakukan hanyalah baru pada tahap mendeteksi lokasi dimana gempa tersebut terjadi serta kedalaman dan tingkat kekuatan gempa itu sendiri apakah berpotensi menimbulkan tsunami atau tidak. Indonesia berdasarkan letak geografisnya memiliki kerentanan potensi terjadinya gempa bumi sehingga sampai saat ini baik pemerintah maupun pihak terkait berusaha untuk dapat mengantisipasi apabila terjadinya bencana gempa bumi tersebut. Terkait dengan tingkat kekuatan gempa yang diukur berdasarkan nilai skala richter (SR) mempunyai pengaruh terhadap potensi-potensi akibat dari gempa tersebut sehingga nilai kekeutan gempa ini dijadikan patokan dalam menilai halhal apa yang bisa dilakukan untuk meminimalisir akibat dari bencana tersebut.

Beberapa penelitian sebelumnya telah banyak dilakukan oleh para peneliti sebelumnya terkait dengan potensi gempa bumi [2]. Penelitian dilakukan oleh [3], dimana pada penelitian ini diusulkan sebuah framework statistic untuk evalusi prediksi gempa bumi. Penelitian lainnya adalah terkait dengan strategi prediksi spasial untuk tanah longsor yang dipicu oleh gempa bumi yang digunakan untuk proses tanggap darurat bencana dilakukan penelitian bidang ini [4]. Penelitian terhadap pengukuran keadaan bahaya gempa bumi pernah dilakukan juga oleh di negara Nepal [5].

Terdapat beberapa metode machine learning yang digunakan dan dterapkan dalam memprediksi gempa bumi ini, diantaranya menggunakan neural network (NN), support vector machine (SVM), linear regression, Decission tree (DT), dan metode lainnya. Penelitian dilakukan oleh [6], dalam penelitiannya mengusulkan model wavelet stasioner, model deret waktu autoregressive dan model ANFIS untuk memprediksi strain energi release gempa bumi. Penelitin lain dilakukan dengan menggunakan ANFIS dan PCA untuk prediksi periode ulang kejadian gema bumi dengan identifikasi pengenalan polaritas mekanisme sumber gempa bumi melalui klasifikasi bola focal [7]. Penelitian selanjutnya dilakukan oleh [8], pada penelitian ini diusulkan sebuah metode pattern informatics yang dimodifikasi dengan panambahan parameter waktu untuk peramalan gempa di pulau Jawa. Pada beberapa penelitian juga data mining digunakan untuk kalsifikasi gempa bumi ini, data mining yang digunakan adalah dengan menggunakan metode Naïve Bayes [9][10].

Penelitian mengenai prediksi efek dari kerusakan gempa bumi dari magnitude (skala richter) dengan menggunakan metode ID3 sudah dilakukan sebelumnya, pada penelitian dilakukan klasifikasi dari efek gempa tersebut [11]. Penelitian penerapan jaringan syaraf tiruan untuk mendapatkan arsitektur terbaik sebetulnya sudah pernah dilakukan oleh untuk memprediksi nilai magnitudo gempa bumi di wilayah provinsi Bengkulu [12][13], selain itu dilakukan pula penerapan NN untuk gempa bumi ini di wilayah sekitar laut merah [14].

Pada artikel ini berbeda dengan penelitian sebelumnya berdasarkan kelebihan yang dimilikinya, neural netwok merupakan salah satu metode terbaik yang dapat digunakan untuk memprediksi data yang berbentuk time series. Metode $\mathrm{NN}$ memiliki kelebihan yang dapat menghasilkan sebuah model prediksi dengan tingkat akurasi yang baik [15]. Permasalahan yang menjadi krusial adalah dalam menentukan nilai parameter dari $\mathrm{NN}$ itu sendiri terutama nilai parameter learning rate, momentum dan training cycles yang harus dilakukan dengan cara manual sehingga menghabiskan banyak waktu dalam pemilihan nilai parameter yang digunakan.

Pada penelitian ini diusulkan sebuah algoritma genetika sebagai metode optimasi[16], dengan kelebihannya yang dimilikinya GA digunakan untuk mengoptimasi model NN yaitu algoritma backpropagation untuk dapat memilih nilai 
parameter terbaik yang dapat digunakan sehingga menghasilkan tingkat akurasi yang terbaik dan nilai tingkat error sekecil mungkin. Kontribusi dan tujuan dari penelitian ini adalah menghasilkan model terbaik untuk dapat memprediksi tingkat kekuatan magnitudo gempa bumi dengan melakukan optimasi model NN sehingga tingkat akurasi yang dihasilkan menjadi lebih baik.

\section{MetODE}

Pada penelitian ini dalam pencarian model didapatkan dengan dilakukan melalui eksperimen. Beberapa tahapan dalam penelitian ini dilakukan sebagai bagian dari proses pencarian model yang diinginkan. Tahapan yang dilakukan adalah setelah dataset didapatkan kemudian dilakukan proses praprocessing data, setelah itu kemudian model dibentuk dan dihasilkan dari proses eksperimen yang dilakukan. Tahapan akhir yang dilakukan adalah melakukan validasi model dan evaluasi model.

\section{A. Data Penelitian}

Data penelitian yang digunakan pada eksperimen ini adalah data yang diambil berasal dari Badan meteorolgi klimatologi dan Geofisika (BMKG) Indonesia dalam kurun waktu mulai dari 1 Januari 2021 s.d 11 Januari 2021[17]. Dataset yang diperoleh berbentuk time series multivariat sehingga dalam prosesnya data tersebut dijadikan univariat karena yang menjadi focus tujuan adalah satu variable saja. Data yang diperoleh mempunyai variable yang terdiri dari tanggal(GMT), Lintang $\left({ }^{\circ}\right)$, Bujur $\left({ }^{\circ}\right)$, kedalaman $(\mathrm{km})$ dan magnitudo (SR). Data yang diperoleh kemudian dilakukan proses praprocessing data untuk memilih variabelyang sesuai yang akan digunakan yaitu hanya varibel magnitudo(SR), gambaran data diperlihatkan pada Gbr.1.

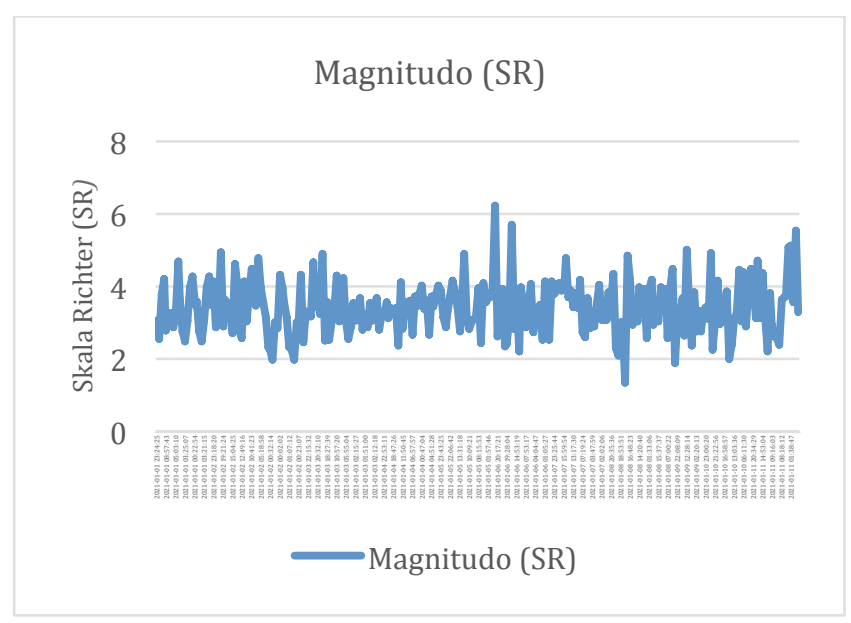

Gbr. 1 Grafik Dataset yang digunakan

\section{B. $\quad$ Validasi dan Evaluasi model}

Dalam mendapatan model yang diinginkan pada penelitian ini validasi model dilakukan dengan menggunakan metode cross validation. Pada proses validasi ini data dibagi menjadi $90 \%$ data training dan $10 \%$ data testing. Pada proses validasi ini untuk performance model diukur dengan menggunakan nilai root mean square error (RMSE) dimana nantinya nilai RMSE yang terkecil merupakan nilai terbaik [18], persamaan untuk mendapatkan nilai tersebut seperti pada persamaan (1).

$$
R M S E=\sqrt{\sum_{i=1}^{n} \frac{(\hat{\mathrm{y}} i-y i)^{2}}{n}}
$$

Pada persamaan (1) dimana $\hat{y}$ adalah nilai prediksi, dan $y$ adalah nilai aktual atau sebenarnya. Evaluasi model dilakukan dengan cara membandingkan model yang didapatkan secara klasik dengan model yang sudah dioptimasi, dimana model $\mathrm{NN}$ dibandingkan dengan model $\mathrm{NN}+\mathrm{GA}$ yang sudah didapatkan.

\section{HASIL DAN PEMBAHASAN}

Dalam penelitian ini eksperimen pencarian model dilakukan dengan menggunakan software Rapidminer studio, sistem operasi windows menggunakan processor core i7, dan memori 8GB. Setiap tahapan dalam eksperimen ini dilakukan dengan terebih dahulu mencari model dengan menggunakan Neural Network klasik dan kemudian pencarian model dilakukan dengan optimasi.

\section{A. Hasil eksperimen Menggunakan Neural Network}

Eksperimen dengan menggunakan NN yang menjadi patokan eksperimen ini adalah nilai parameter yang digunakan. Pada tahapan pertama ini nilai parameter telah diatur dan ditentukan dimana nilai learning rate $=0,01$, training cycles $=200$, serta momentum $=0,9$. Beberapa kombinasi arsitektur jaringan $\mathrm{NN}$ ditentukan dalam penentuan model ini seperti pengaturan jumlah neuron input, dan jumlah neuron lapisan hidden.

Pada hasil eksperimen pertama adalah ditentukan parameter windowing $=3$, dan telah didapatkan model seperti diperlihatkan pada Tabel I, Tabel II, dan Tabel III.

TABEL I

MODEL NN DENGAN ARSITEKTUR 3-3-1

\begin{tabular}{|c|c|l|c|c|}
\hline Model & k-Fold & Sampling & RMSE & Squared_error \\
\hline $3-3-1$ & 10 & linear & 0.733 & 0.565 \\
\hline & & shuffled & 0.738 & 0.558 \\
\hline & 8 & linear & 0.741 & 0.564 \\
\hline & & shuffled & 0.748 & 0.572 \\
\hline & 6 & linear & 0.741 & 0.561 \\
\hline & & shuffled & 0.720 & 0.531 \\
\hline & 4 & linear & 0.733 & 0.551 \\
\hline & & shuffled & 0.776 & 0.618 \\
\hline & 2 & linear & 0.786 & 0.619 \\
\hline & & shuffled & 0.731 & 0.542 \\
\hline
\end{tabular}


TABEL II

MODEL NN DENGAN ARSITEKTUR 3-4-1

\begin{tabular}{|c|c|l|c|c|}
\hline Model & k-Fold & Sampling & RMSE & Squared_error \\
\hline $3-4-1$ & 10 & linear & 0.734 & 0.567 \\
\hline & & shuffled & 0.750 & 0.575 \\
\hline & 8 & linear & 0.739 & 0.561 \\
\hline & & shuffled & 0.784 & 0.631 \\
\hline & 6 & linear & 0.756 & 0.584 \\
\hline & & shuffled & 0.734 & 0.552 \\
\hline & 4 & linear & 0.746 & 0.573 \\
\hline & & shuffled & 0.750 & 0.577 \\
\hline & 2 & linear & 0.773 & 0.613 \\
\hline & & shuffled & 0.826 & 0.683 \\
\hline
\end{tabular}

TABEL III

MODEL NN DENGAN ARSITEKTUR 3-5-1

\begin{tabular}{|c|c|l|c|c|}
\hline Model & k-Fold & Sampling & RMSE & Squared_error \\
\hline $3-5-1$ & 10 & linear & 0.727 & 0.556 \\
\hline & & shuffled & 0.723 & 0.531 \\
\hline & 8 & linear & 0.756 & 0.592 \\
\hline & & shuffled & 0.726 & 0.537 \\
\hline & 6 & linear & 0.730 & 0.545 \\
\hline & & shuffled & 0.761 & 0.593 \\
\hline & 4 & linear & 0.735 & 0.553 \\
\hline & & shuffled & 0.761 & 0.583 \\
\hline & 2 & linear & 0.759 & 0.583 \\
\hline & & shuffled & 0.741 & 0.552 \\
\hline
\end{tabular}

Model dengan menggunakan arsitektur input neuron sebanyak 3 yang diperlihatkan Tabel I, Tabel II, dan Tabel II menghasilkan nilai RMSE terbaik sebesar 0,720. Model ini menggunakan arsitektur 3-3-1 menggunakan $k$-fold $=6$ dengan menggunakan teknik sampling shuffled.

Tahapan eksperimen selanjutnya adalah dengan menentukan nilai parameter inputan yang berbeda yaitu parameter windowing $=4$. Pada model ini input data di setting berjumlah 4 inputan dan untuk jumlah neuron lapisan hidden juga dilakukan perubahan. Model yang didapatkan dari tahapan ini seperti diperlihatkan pada Tabel IV, Tabel V, dan Tabel VI.

TABEL IV

MODEL NN DENGAN WINDOWING = 4, ARSITEKTUR 4-4-1

\begin{tabular}{|c|c|l|c|c|}
\hline Model & k-Fold & Sampling & RMSE & Squared_error \\
\hline $4-4-1$ & 10 & linear & 0.766 & 0.601 \\
\hline & & shuffled & 0.748 & 0.748 \\
\hline & 8 & linear & 0.739 & 0.565 \\
\hline & & shuffled & 0.733 & 0.543 \\
\hline & 6 & linear & 0.752 & 0.582 \\
\hline & & shuffled & 0.779 & 0.608 \\
\hline & 4 & linear & 0.733 & 0.552 \\
\hline & & shuffled & 0.731 & 0.537 \\
\hline & 2 & linear & 0.751 & 0.573 \\
\hline & & shuffled & 0.757 & 0.573 \\
\hline
\end{tabular}

TABEL V

MODEL NN DENGAN WINDOWING = 4, ARSITEKTUR 4-5-1

\begin{tabular}{|c|c|l|c|c|}
\hline Model & k-Fold & Sampling & RMSE & Squared_error \\
\hline $4-5-1$ & 10 & linear & 0.718 & 0.543 \\
\hline & & shuffled & 0.753 & 0.579 \\
\hline & 8 & linear & 0.770 & 0.615 \\
\hline
\end{tabular}

\begin{tabular}{|l|c|l|c|c|}
\hline & & shuffled & 0.739 & 0.554 \\
\hline & 6 & linear & 0.784 & 0.631 \\
\hline & & shuffled & 0.759 & 0.587 \\
\hline & 4 & linear & 0.749 & 0.574 \\
\hline & & shuffled & 0.775 & 0.609 \\
\hline & 2 & linear & 0.782 & 0.613 \\
\hline & & shuffled & 0.820 & 0.678 \\
\hline
\end{tabular}

TABEL VI

MODEL NN DENGAN WINDOWING = 4, ARSITEKTUR 4-6-1

\begin{tabular}{|c|c|l|c|c|}
\hline Model & k-Fold & Sampling & RMSE & Squared_error \\
\hline $4-6-1$ & 10 & linear & 0.734 & 0.568 \\
\hline & & shuffled & 0.728 & 0.540 \\
\hline & 8 & linear & 0.739 & 0.569 \\
\hline & & shuffled & 0.728 & 0.535 \\
\hline & 6 & linear & 0.786 & 0.628 \\
\hline & & shuffled & 0.780 & 0.623 \\
\hline & 4 & linear & 0.722 & 0.538 \\
\hline & & shuffled & 0.767 & 0.593 \\
\hline & 2 & linear & 0.789 & 0.625 \\
\hline & & shuffled & 0.804 & 0.647 \\
\hline
\end{tabular}

Berdasarkan pada Tabel IV, Tabel V dan Tabel VI memperlihatkan nilai RMSE yang berbeda, ini diakibatkan karena arsitektur dan nilai arameer yang digunakan berbeda, dan nilai terbaik dihasilkan dengan model NN yang menggunakan arsitektur 4-5-1 yaitu sebesar 0,718. Model ini menggunakan $k$-Fold $=10$, dan menggunakan teknik sampling linear.

Eksperimen selanjutnya adalah dengan melakukan perubahan jumlah neuron input, dimana nilai windows $=5$. Pada model ini nilai input berjumlah 5 yang kemudian diikuti dengan perubahan pada jumlah neuron lapisan hidden. Dari model yang dibuat didapatkan hasil ekperimen nilai RMSE seperti ditunjukan pada Tabel VII, Tabel VIII, dan table IX.

TABEL VII

MODEL NN DENGAN WINDOWING = 5, ARSITEKTUR 5-4-1

\begin{tabular}{|c|c|l|c|c|}
\hline Model & k-Fold & Sampling & RMSE & Squared_error \\
\hline $5-4-1$ & 10 & linear & 0.727 & 0.547 \\
\hline & & shuffled & 0.743 & 0.557 \\
\hline & 8 & linear & 0.737 & 0.565 \\
\hline & & shuffled & 0.764 & 0.596 \\
\hline & 6 & linear & 0.758 & 0.586 \\
\hline & & shuffled & 0.748 & 0.567 \\
\hline & 4 & linear & 0.762 & 0.585 \\
\hline & & shuffled & 0.753 & 0.569 \\
\hline & 2 & linear & 0.746 & 0.566 \\
\hline & & shuffled & 0.776 & 0.603 \\
\hline
\end{tabular}

TABEL VIII

MODEL NN DENGAN WINDOWING = 5, ARSITEKTUR 5-5-1

\begin{tabular}{|c|c|l|c|c|}
\hline Model & k-Fold & Sampling & RMSE & Squared_error \\
\hline $5-5-1$ & 10 & linear & 0.740 & 0.575 \\
\hline & & shuffled & 0.748 & 0.566 \\
\hline & 8 & linear & 0.739 & 0.569 \\
\hline & & shuffled & 0.771 & 0.601 \\
\hline & 6 & linear & 0.782 & 0.617 \\
\hline & & shuffled & 0.763 & 0.587 \\
\hline
\end{tabular}




\begin{tabular}{|l|l|l|l|l|}
\hline & 4 & linear & 0.779 & 0.612 \\
\hline & & shuffled & 0.743 & 0.555 \\
\hline & 2 & linear & 0.793 & 0.630 \\
\hline & & shuffled & 0.839 & 0.705 \\
\hline
\end{tabular}

TABEL IX

MODEL NN DENGAN WINDOWING = 5, ARSITEKTUR 5-6-1

\begin{tabular}{|c|c|l|c|c|}
\hline Model & k-Fold & Sampling & RMSE & Squared_error \\
\hline $5-6-1$ & 10 & linear & 0.725 & 0.558 \\
\hline & & shuffled & 0.728 & 0.537 \\
\hline & 8 & linear & 0.764 & 0.595 \\
\hline & & shuffled & 0.756 & 0.578 \\
\hline & 6 & linear & 0.753 & 0.588 \\
\hline & & shuffled & 0.761 & 0.584 \\
\hline & 4 & linear & 0.755 & 0.586 \\
\hline & & shuffled & 0.773 & 0.602 \\
\hline & 2 & linear & 0.838 & 0.704 \\
\hline & & shuffled & 0.801 & 0.642 \\
\hline
\end{tabular}

Nilai RMSE terbaik dengan menggunakan windowing=5 berdasarkan pada Tabel VII, Tabel VIII, dan Tabel IX adalah menghasilkan nilai $\mathrm{RMSE}=0,725$ dengan menggunakan arsitektur model 5-6-1 dan $\mathrm{K}$-fold=10 serta menggunakan teknik sampling linear.

\section{B. Hasil eksperimen Optimasi Model NN + GA}

Upaya peningkatan akurasi berdasarkan nilai RMSE terbaik yang didapatkan oleh model klasik NN, maka tahapan berikutnya adalah melakukan optimasi agar terjadinya peningkatan akurasi. Optimasi ini dilakukan dengan melakukan penerapan algoritma genetika (GA) yang digunakan dalam mengoptimalkan nilai parameter pada NN. Penentuan nilai parameter terbaik ini dilakukan oleh GA dengan menggunakan beberapa parameter GA yang sudah diatur untuk mendapatkan model terbaik.

Pada tahapan ini untuk parameter GA ditentukan yaitu parameter max generation $=50$, population size $=10$, selection type=tournament, dan mutation_type=gaussian_mutation. Berdasarkan nilai parameter yang sudah ditentukan menghasilkan model dengan nilai $\mathrm{RMSE}=0,708$. Pada eksperimen ini terdapat perubahan nilai, dimana nilai RMSE yang dihasilkan lebih baik dan lebih kecil dari model NN klasik. Nilai parameter NN yang sudah didapatkan setelah dilakukan optimasi diperlihatkan pada TABEL X.

TABEL X

NILAI PARAMETER NN SETELAH DI OPTIMASI

\begin{tabular}{|c|l|l|}
\hline No. & Parameter NN & Nilai \\
\hline 1 & Training_cycles & 16 \\
\hline 2 & Learning_rate & 0.05720703801983846 \\
\hline 3 & momentum & 0.09452878676925322 \\
\hline
\end{tabular}

Berdasarkan nilai parameter terbaik yang sudah didapatkan menghasilkan model arsitektur NN dengan kombinasi 4-5-1 dimana terdiri dari 4 neuron input, 5 neuron hidden, dan I neuron output. Arsitektur NN yang sudah diperoleh diperlihatkan pada Gbr.2

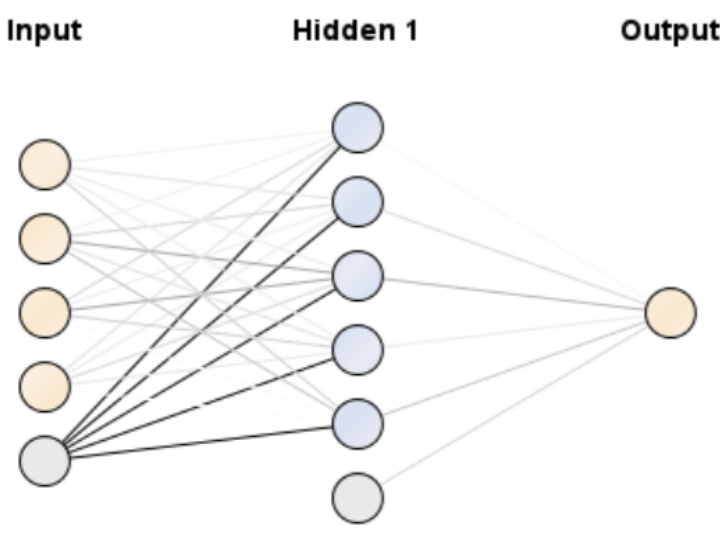

Gbr. 2 Arsitektur model NN terbaik yang dihasilkan

\section{Evaluasi Model}

Berdasarkan hasil penelitian eksperimen yang telah dilakukan dengan melakukan berbagai model untuk mendapatkan model terbaik didapatkan hasil yang cukup baik. Optimasi yang telah dilakukan telah memperoleh nilai RMSE yang lebih baik, sehingga upaya optimasi ini sudah cukup berhasil. Hasil eksperimen yang telah didapatkan perbandingan dari kedua model terbaik seperti diperihatkan pada Tabel XI.

TABEL XI

EVALUASI MODEL

\begin{tabular}{|l|l|l|}
\hline Model & RMSE & Squared_error \\
\hline Neural Network (NN) & 0,718 & 0,543 \\
\hline NN+GA (diusulkan) & 0,708 & 0,525 \\
\hline
\end{tabular}

Evaluasi Model

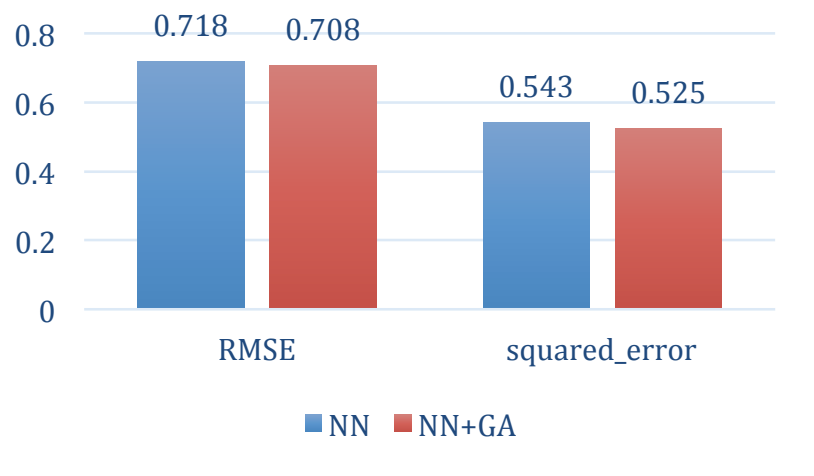

Gbr. 3 Grafik komparasi model NN dan NN+GA

Dari Tabel XI terlihat bahwa terdapat perbedaan nilai RMSE, dimana model dengan menggunakan $\mathrm{NN}$ memeproleh nilai $\mathrm{RMSE}=0,718$ sedangkan model dengan $\mathrm{NN}+\mathrm{GA}$ memperoleh nilai $\mathrm{RMSE}=0,708$. Perbedaan ini memberikan hasil model dengan menggunakan $\mathrm{NN}+\mathrm{GA}$ lebih baik dibandingkan dengan $\mathrm{NN}$ klasik dimana terlihat nilai $\mathrm{NN}+\mathrm{GA}$ lebih kecil dan ini memberikan indicator model yang diusulkan lebih baik dari model klasik. 


\section{KESIMPULAN}

Penerapan algoritma genetika dalam upaya optimasi nilai parameter NN dalam penelitian ini telah memeberikan perubahan pda nilai akurasi RMSE yang disapatkan sehingga model yang diusukan menjadi lebih baik. Prediksi kekuatan gempa bumi di Indonesia berdasarkan nilai magnitudo dalam penelitian ini sudah dapat dilakukan dengan menggunakan model yag didapatkan sehingga dalam prediksi ini dapat dijadikan sebagai bahan pendukung keputusan pihak terkait baik pemerintah maupun instansi terkait dalam upaya mitigasi bencana untuk mengurangi resiko bencana gempa bumi yang terjadi.

Model yang didapatkan tentukan memerlukan sebuha peningkatan akurasi yang lebih baik sehingga untuk penelitian kedepannya diperlukan eksperimen lanjutan terutama dengan menggunakan metode dan algoritma lainnya agar dapat membandingkan model terbaik yang dapat diterapkan untuk prediksi kekuatan gempa bumi ini.

\section{REFERENSI}

[1] R. Sorkhabi, Earthquake hazard, risk and disasters. Academic Press, 2014.

[2] T. Tupan, N. R. Widuri, and R. Rachmawati, "ANALISIS BIBLIOMETRIK PUBLIKASI ILMIAH TENTANG PREDIKSI GEMPA BUMI BERBASIS DATA SCOPUS PERIODE 2015-2020," Libr. J. Perpust., vol. 8 , no. 1,2020

[3] Z.-H. Jiao and X. Shan, "Statistical framework for the evaluation of earthquake forecasting: A case study based on satellite surface temperature anomalies," J. Asian Earth Sci., vol. 211, p. 104710, May 2021, doi: 10.1016/j.jseaes.2021.104710.

[4] S. Ma, C. Xu, and X. Shao, "Spatial prediction strategy for landslides triggered by large earthquakes oriented to emergency response, mid-term resettlement and later reconstruction," Int. J. Disaster Risk Reduct., vol. 43, p. 101362, Feb. 2020, doi: 10.1016/j.ijdrr.2019.101362.

[5] S. Pasari, Y. Sharma, and Neha, "Quantifying the current state of earthquake hazards in Nepal," Appl. Comput. Geosci., vol. 10, p. 100058, Jun. 2021, doi: 10.1016/j.acags.2021.100058.

[6] S. Rohadi, "APLIKASI WAVELET STASIONER DALAM PREDIKSI AKTIVITAS STRAIN ENERGY RELEASE GEMPABUMI DI ZONA SUBDUKSI JAWA," J. Meteorol. dan Geofis., vol. 9, no. 1, May 2014, doi: 10.31172/jmg.v9i1.20.

[7] W. Setyonegoro and N. AZ, "PROTOTIPE MODEL PREDIKSI PERIODE ULANG KEJADIAN GEMPA BUMI DENGAN IDENTIFIKASI PENGENALAN POLARITAS MEKANISME SUMBER GEMPA BUMI MELALUI KLASIFIKASI BOLA FOCAL MENGGUNAKAN TEKNIK ANFIS DAN PCA," Telemat. MKOM, vol. 7, no. 1, pp. 57-71, Jun. 2016, Accessed: Aug. 06, 2021. [Online]. Available: https://journal.budiluhur.ac.id/index.php/telematika/article/view/130.

[8] A. Wibowo, A. Insani, and B. Nurdiyanto S., "Modifikasi Pattern Informatics untuk Prediksi Hotspot Aktivitas Seismik pada Gempa di Pulau Jawa," J. Nas. Tek. Elektro dan Teknol. Inf., vol. 6, no. 2, Jun. 2017, doi: 10.22146/jnteti.v6i2.305.

[9] D. Maulana and R. Rahmanto, "PENERAPAN DATA MINING UNTUK MENGANALISIS DATA BENCANA GEMPA BUMI DI KEPULAUAN MALUKU PADA BMKG MENGGUNAKAN NAÏVE BAYES ALGORITHM," SIGMA - J. Teknol. Pelita Bangsa, vol. 10, no. 3, 2020 .

[10] D. P. Utomo and B. Purba, "Penerapan Datamining pada Data Gempa Bumi Terhadap Potensi Tsunami di Indonesia," Pros. Semin. Nas. Ris. Inf. Sci., vol. 1, p. 846, Sep. 2019, doi: 10.30645/senaris.v1i0.91.

[11] L. Irawan, L. H. Hasibuan, and F. Fauzi, "ANALISA PREDIKSI EFEK KERUSAKAN GEMPA DARI MAGNITUDO (SKALA RICHTER) DENGAN METODE ALGORITMA ID3 MENGGUNAKAN APLIKASI
DATA MINING ORANGE," J. Teknol. Inf. J. Keilmuan dan Apl. Bid. Tek. Inform., vol. 14, no. 2, pp. 189-201, Aug. 2020, doi: 10.47111/jti.v14i2.1079. [12] W. Agwil, "PENERAPAN JARINGAN SARAF TIRUAN PADA DATA GEMPA BUMI DI PROVINSI BENGKULU," J. Stat. Univ. Muhammadiyah Semarang, vol. 8, no. 2, p. 152, Nov. 2020, doi: 10.26714/jsunimus.8.2.2020.152-158.

[13] F. Firdausa, "Prediksi dan Analisis Data Gempa Bumi di Provins Bengkulu dengan Metode Artificial Neural Network," CANTILEVER, vol. 8, no. 2, pp. 45-49, Jan. 2020, doi: 10.35139/cantilever.v8i2.5.

[14] A. S. N. Alarifi, N. S. N. Alarifi, and S. Al-Humidan, "Earthquakes magnitude predication using artificial neural network in northern Red Sea area," J. King Saud Univ. - Sci., vol. 24, no. 4, pp. 301-313, Oct. 2012, doi: 10.1016/j.jksus.2011.05.002.

[15] S. Sri Lakshmi and R. K. Tiwari, "Model dissection from earthquake time series: A comparative analysis using modern non-linear forecasting and artificial neural network approaches," Comput. Geosci., vol. 35, no. 2, pp. 191-204, Feb. 2009, doi: 10.1016/j.cageo.2007.11.011.

[16] R. L. Haupt, S. E. Haupt, and A. J. Wiley, ALGORITHMS PRACTICAL GENETIC ALGORITHMS.

[17] "DATA ONLINE - PUSAT DATABASE - BMKG." https://dataonline.bmkg.go.id/home (accessed Dec. 06, 2020).

[18] T. Chai and R. R. Draxler, "Root mean square error (RMSE) or mean absolute error (MAE)? - Arguments against avoiding RMSE in the literature," Geosci. Model Dev., vol. 7, no. 3, pp. 1247-1250, Jun. 2014, doi: 10.5194/gmd-7-1247-2014. 